\title{
Formação versus vulnerabilidades: contribuições da educação empreendedora promovida pela Ativa Incubadora de Empresas do IFMT
}

\author{
Training versus vulnerabilities: contributions of entrepreneurial education promoted by the Active \\ Incubator of IFMT Companies
}

Formación versus vulnerabilidades: aportes de la educación emprendedora impulsada por la

Incubadora Activa de Empresas IFMT

Recebido: 19/08/2021 | Revisado: 25/08/2021 | Aceito: 26/08/2021 | Publicado: 28/08/2021

\author{
Joelias Silva Pinto Júnior \\ ORCID: https://orcid.org/0000-0001-6810-5878 \\ Instituto Federal de Mato Grosso, Brasil \\ E-mail: joeliasjunior@gmail.com \\ Anderson Ricardo Silvestro \\ ORCID: https://orcid.org/0000-0002-7101-2522 \\ Instituto Federal de Mato Grosso, Brasil \\ E-mail: ricardo.silvestro@bag.ifmt.edu.br \\ Carlos Miguel Espedito Santos Shirmer \\ ORCID: https://orcid.org/0000-0002-7925-1093 \\ Universidade Federal de Mato Grosso, Brasil \\ E-mail: carlos-schirmer2014@ hotmail.com.br \\ Eduardo Ribeiro Mueller \\ ORCID: https://orcid.org/0000-0002-6486-919X \\ Universidade Federal de Mato Grosso, Brasil \\ E-mail: edurmueller@hotmail.com
}

\begin{abstract}
Resumo
Este trabalho analisou o contexto de formação de uma importante incubadora de empresas do Centro Oeste brasileiro, a Ativa Incubadora do Instituto Federal de Mato Grosso - IFMT. Teve como objetivo entender como a formação oferecida pela Ativa incubadora do IFMT contribui para a superação de situações de vulnerabilidade evidenciadas no diagnóstico inicial do incubado. O público pesquisado foram os próprios incubados da Ativa deste no ano de 2021 . A metodologia foi qualitativa e o método um estudo de caso. Os procedimentos metodológicos se pautaram em três etapas inerentes à incubação desenvolvida: 1) evidenciação de vulnerabilidades a partir do diagnóstico realizado com os incubados, 2) evidenciação das etapas de formação oferecidas pela Ativa Incubadora do IFMT por meio do Curso de Competências Empreendedoras, e 3) possibilidades da formação para a superação de vulnerabilidades. A análise também se deu em etapas: 1) confronto entre as vulnerabilidades encontradas com maior frequência e os conceitos oferecidos na formação capazes de suportar esta superação; e 2) análise da formação com base em premissas educacionais que estruturam teoricamente a formação prática - uma característica do curso de competências empreendedoras da Ativa Incubadora do IFMT. As análises e dados mostraram que a contribuição da formação oferecida pelo Ativa está duplamente pautada para a superação de vulnerabilidades, pois de um lado tem um currículo estruturado com conceitos capazes de confrontar as vulnerabilidades de seus incubados, e de outro pratica acompanhamentos que analisam a aplicação prática da formação oferecida, oferecendo soluções por meio de atendimentos diretos e consultorias.
\end{abstract}

Palavras-chave: Incubação; Educação empreendedora; Aprendizagem pela prática; Superação de vulnerabilidades.

\begin{abstract}
This work analyzed the context of formation of an important business incubator in the Brazilian Midwest, the Active Incubator of the Federal Institute of Mato Grosso - IFMT. Its objective was to understand how the training offered by the IFMT's Active Incubator contributes to overcoming situations of vulnerability evidenced in the initial diagnosis of the incubator. The researched public were the Ativa's own incubators in 2021. The methodology was qualitative and the method a case study. The methodological procedures were based on three stages inherent to the developed incubation: 1) disclosure of vulnerabilities from the diagnosis made with the incubated, 2) disclosure of the training stages offered by the IFMT Incubator Active through the Entrepreneurial Skills Course, and 3 ) possibilities of training to overcome vulnerabilities. The analysis also took place in stages: 1) confrontation between the most frequently found vulnerabilities and the concepts offered in training capable of supporting this overcoming; and 2) analysis of training based on educational assumptions that theoretically structure the practical training - a
\end{abstract}


characteristic of the entrepreneurial skills course of the Active Incubator at IFMT. The analyzes and data showed that the contribution of the training offered by Ativa is doubly guided towards overcoming vulnerabilities, since on the one hand it has a structured curriculum with concepts capable of confronting the vulnerabilities of its incubated companies, and on the other hand it practices follow-ups that analyze the application practice of the training offered, offering solutions through direct assistance and consultancy.

Keywords: Incubation; Entrepreneurial education; Learning through practice; Overcoming vulnerabilities.

\section{Resumen}

Este trabajo analizó el contexto de formación de una importante incubadora de empresas en el Medio Oeste brasileño, la Incubadora Activa del Instituto Federal de Mato Grosso - IFMT. El objetivo fue comprender cómo la capacitación ofrecida por la Incubadora Activa del IFMT contribuye a superar situaciones de vulnerabilidad evidenciadas en el diagnóstico inicial de la incubadora. El público investigado fueron las propias incubadoras de Ativa en 2021. La metodología fue cualitativa y el método un estudio de caso. Los procedimientos metodológicos se basaron en tres etapas inherentes a la incubación desarrollada: 1) divulgación de vulnerabilidades a partir del diagnóstico realizado con los incubados, 2) divulgación de las etapas de capacitación que ofrece la Incubadora IFMT Activa a través del Curso de Habilidades Empresariales, y 3) posibilidades de formación para superar vulnerabilidades. El análisis también se realizó en etapas: 1) confrontación entre las vulnerabilidades encontradas con mayor frecuencia y los conceptos ofrecidos en la formación capaces de apoyar esta superación; y 2) análisis de la formación a partir de supuestos educativos que estructuran teóricamente la formación práctica, característica del curso de habilidades emprendedoras de la Incubadora Activa del IFMT. Los análisis y datos mostraron que el aporte de la formación que ofrece Ativa está doblemente orientado a la superación de vulnerabilidades, ya que por un lado cuenta con un currículo estructurado con conceptos capaces de afrontar las vulnerabilidades de sus empresas incubadas, y por otro lado practica seguimientos que analizan la práctica de aplicación de la formación ofrecida, ofreciendo soluciones a través de la asistencia directa y la consultoría.

Palabras clave: Incubación; Educación emprendedora; Aprendiendo através de la práctica; Superando vulnerabilidades.

\section{Introdução}

A ideia de incubação está conceitualmente posta como capacitação ao empreendedorismo, mas ela é mais do que isso! A dialética em torno desse fenômeno social debate, ao mesmo tempo, a concepção de negócio puramente capitalista e, contraditoriamente, inclusão social, economia solidária, cooperativismo, associativismo etc. A participação das extensões universitárias chancelam essa dialeticidade dada aos processos de incubação, pois derivam delas muitas formações empreendedoras de caráter mais humano. A dialética a que nos referimos cabe na ideia de ter um negócio onde se ganha mais dinheiro crescendo junto, e não competindo. Isso é muito vivo nas incubações.

A palavra empreendedorismo tem na sua etimologia o termo entrepreneur, que significa pessoa fora do comum, capaz de fazer a diferença, pessoa visionária, capaz de gerar valor para a sociedade (Hisrish, 1986). A expansão desse significado se tornou objeto de análise de vários pesquisadores. Fillion (1999), por exemplo, propõe duas escolas teóricas que caracterizam o empreendedorismo e a atividade empreendedora. A escola economista dá outros sentidos ao temo empreender, entre eles liderança, sucesso, inovação, pouco receio às mudanças, foco em aproveitar as oportunidades de mercado. A escola comportamentalista foca na análise e descrição do comportamento dos empreendedores e sua influência na criação de negócios (Fonseca et. al., 2020).

A Ativa Incubadora do IFMT, criada em 2004, transitou ao longo desses 17 anos de existência pelas duas escolas, economista e comportamentalista. No início prospectava e apoiava projetos e empreendimentos em agronegócio provenientes de comunidades rurais e dos seus discentes. Em 2015, seis anos após a criação dos Institutos Federais, a incubadora foi alocada na reitoria e subordinada administrativamente à Pró-reitoria de Extensão, ampliando seus objetivos e potencializando sua atuação proporcionando participação de todos os Campi no processo de incubação.

A partir de 2017, com a aprovação de novo regimento, a Ativa passou a regulamentar e acompanhar empresas juniores no âmbito do IFMT com estratégia de gestão voltada à sensibilização da comunidade interna para a temática empreendedorismo e incubação de negócios. Neste mesmo ano foi criado o Fórum de Educação Empreendedora, evento 
itinerante de divulgação das ações empreendedoras da instituição. Também neste ano, como resultado deste novo regulamento, a incubadora passa a adotar o formado de incubadora em rede, onde sua gestão é centralizada na reitoria, mas possui instâncias representativas que podem ser instaladas nos Campi que se habilitam para tal, denominadas Núcleos Incubadores. Em 2019 foi criado o Núcleo Incubador Dinâmica, no Campus Barra do Garças e, desde então, este passa a se destacar por ser o único entre os 14 núcleos vigente da Ativa a realizar processos de incubação de empresas.

Este trabalho teve como objetivo entender como a formação oferecida pelo Núcleo Incubador Dinâmica da Ativa Incubadora do IFMT contribui para a superação de situações de vulnerabilidade evidenciadas no diagnóstico inicial do incubado. O público pesquisado são os próprios incubados do núcleo envolvidos no projeto de incubação no ano de 2021 e foi uma investigação que requereu que voltássemos nosso foco à aprendizagem empreendedora, adquirida a partir da formação oferecida pelo núcleo, e como esta aprendizagem poderia se traduzir em educação empreendedora capaz de conduzir o incubado à superação de vulnerabilidades em seu negócio.

\section{Metodologia}

Esta é uma investigação com foco em conhecimento de causa, evidenciada por meio do gerenciamento de um empreendimento em meio a uma crise de saúde mundial, a pandemia provocada pelo vírus da COVID 19. Deriva desta avaliação nossa forma de compreender nuances do processo de enfrentamento de dificuldades em relação a este contexto de crise; ao mesmo tempo, esta avaliação é capaz de revelar estratégias e conhecimentos inerentes à ação de empreender, bem como as vulnerabilidades inerentes a qualquer empreendimento não consolidado. A interpretação que daremos a esses resultados requer um método capaz de qualificá-la, e em função das características optamos por classificar esta investigação como pesquisa qualitativa.

Os métodos qualitativos valorizam a interpretação por parte do pesquisador com suas opiniões sobre o fenômeno em estudo (Pereira et al., 2018). Características como coleta direta de dados preferencialmente descritivos em ambiente natural traduzem a investigação proposta neste trabalho, e corroboram com seu caráter qualitativo.

A pesquisa qualitativa não está moldada na mensuração, a exemplo de muitos casos das ciências naturais, e a exemplo deste caso; e quando a adotamos não estamos interessados em padronizar uma situação, muito menos garantir a representatividade por amostragem aleatória dos participantes (Flick, 2013). O foco da pesquisa qualitativa é compreender e aprofundar os fenômenos que são explorados a partir da perspectiva dos participantes em um ambiente natural e em relação ao contexto (Sampieri, 2013).

A metodologia de pesquisa é um estudo de caso, pois não se trata da evidenciação da consciência de incubados acerca de suas vulnerabilidades, mas sim de como suas vulnerabilidades podem ser superadas a partir de uma formação. Ter vulnerabilidades e participar de formação é comum a todas as incubadoras. Analisar a especificidade de uma única formação torna nossa investigação um estudo de caso.

Em direito, administração e medicina foram e ainda são usados como recurso didático, seja com a finalidade de ilustrar o uso de um procedimento, seja para estimular, em situação de ensino, o debate de um tema. Muito popular atualmente é o método de cases na área de administração, que visa mostrar, por meio de um caso exemplar, como uma empresa ou organização pode se estruturar, resolver problemas, vencer (André, 2005, p. 13 - grifos da autora).

Corroborando com a qualificação deste estudo como um estudo de caso, Bogdan e Biklen (1994) sugerem espírito prático na escolha da investigação, assim como da forma de coletar dados. Há uma forte ressignificação, por exemplo, na forma como empresas passaram/passarão a utilizar redes sociais no gerenciamento de produtos e recursos após a pandemia. Isso é consequência de certa obrigatoriedade em se reinventar para sobreviver no mercado, em se tornar competitiva ou 
simplesmente para seguir uma tendência social. Interpretar isso é uma forma de manifestar espírito prático na concepção dos autores.

Os procedimentos metodológicos se pautaram em três etapas inerentes á incubação desenvolvida pelo Núcleo Incubador do IFMT: 1) evidenciação de vulnerabilidades a partir do diagnóstico realizado com os incubados, 2) evidenciação das etapas de formação oferecidas pelo Núcleo Incubador do IFMT por meio do Curso de Competências Empreendedoras, e 3) possibilidades da formação para a superação de vulnerabilidades.

O diagnóstico se deu por meio de um questionário semiestruturado com 7 seções no Google formulários: 1) informações pessoais, 2) informações do empreendimento, 3) situação econômica do empreendimento, 4) gestão, 5) uso de tecnologia, 6) dificuldades, e 7) disponibilidade e motivação. Como nosso objetivo estava voltado à evidenciação de vulnerabilidades, demos ênfase nesta abordagem às questões que julgamos mais relevantes nesse contexto, a saber:

1. Idade e gênero do incubado/da incubada.

2. Qual seu nível de escolaridade?

3. Qual o ramo de atividade do empreendimento?

4. Possui CNPJ?

5. Quanto tempo de funcionamento tem o empreendimento?

6. Qual a quantidade de pessoas que atuam no empreendimento (Sócios e funcionários)?

7. Qual seu nível de conhecimento sobre marketing digital?

8. Você utiliza alguma ferramenta ou estratégia de divulgação e marketing? Explique.

9. Detalhe as dificuldades enfrentadas pelo seu empreendimento quanto à utilização de tecnologias.

10. Quais acredita serem os maiores pontos FRACOS ou de MELHORIA internos e externos de sua empresa atualmente?

11. Que tipo de auxílio você espera e como acha que o processo de incubação poderia te auxiliar?

Nossa amostragem selecionou dez empresas de um ciclo de incubação atual (vinculado a um projeto de 2021). Como $80 \%$ do nosso público alvo deste ano foram mulheres, mantivemos esta proporção na escolha das dez. A escolha se deu por sorteio envolvendo 21 empreendimentos.

A análise de evidenciação da contribuição da formação para a superação de vulnerabilidades se deu em duas etapas: 1) confronto entre as vulnerabilidades encontradas com maior frequência e os conceitos oferecidos na formação capazes de suportar esta superação; e 2) análise da formação com base em premissas educacionais que estruturam teoricamente a formação prática - uma característica do curso de competências empreendedoras do Núcleo Incubador do IFMT. A seguir apresentamos e discutimos os resultados encontrados.

\section{Resultados e discussão}

\subsection{Vulnerabilidades evidenciadas pelo diagnóstico}

O diagnóstico é a etapa inicial de averiguação das condições do empreendimento. Fundamental em qualquer processo de incubação, o diagnóstico é capaz de revelar a real situação da empresa evidenciando as formas de organização e planejamento do negócio.

Na Ativa Incubadora do IFMT a metodologia do diagnóstico é baseada em dois principais pilares: os cinco eixos (Empreendedor, Tecnológico, Financeiro, Mercado e Gestão) da metodologia CERNE de incubação, internacionalmente conhecida, e nos princípios do Planejamento Estratégico. Neste trabalho, analisamos especificamente uma das ferramentas do Planejamento Estratégico, que compõe a metodologia, a análise SWOT. Do inglês Strengths, Weaknesses, Opportunities and 
Threats, respectivamente, Forças, Fraquezas, Oportunidades e Ameaças, a matriz SWOT é muito utilizada no mundo (Helms; Nixon; 2010) para orientar tomadas de decisão em relação a situações complexas de modo a melhorar os resultados do negócio. Um dos trabalhos verificados por nós (Costa Júnior et al, 2021) apresentou densa fundamentação teórica sobre esta metodologia e analisou conceitualmente a matriz SWOT apresentando novas subcategorias de avaliação de oportunidades e ameaças. Não nos aprofundaremos na discussão da matriz SWOT por não constituir foco do nosso trabalho.

O roteiro para produção do diagnóstico é estruturado num painel de gestão contendo espaços apropriados para, dentro do prazo específico de incubação da empresa, estruturar um plano de ação, plano de capacitação, objetivos estratégicos, missão, valores, visão, além da própria análise SWOT, onde são elencados pontos fortes, fracos, oportunidades e ameaças. Apresentamos inicialmente, no Quadro 1, uma caracterização dos incubados da nossa amostragem.

Quadro 1: Caracterização dos empreendimentos estudados.

\begin{tabular}{|c|c|c|c|c|c|c|c|c|}
\hline $\begin{array}{l}\text { INCUBADOS/I } \\
\text { NCUBADAS }\end{array}$ & IDADE & GÊNERO & RAMO & $\begin{array}{l}\text { ESCOLAR } \\
\text { IDADE }\end{array}$ & $\begin{array}{c}\text { POSSUI } \\
\text { CNPJ }\end{array}$ & $\begin{array}{l}\text { TEMPO DE } \\
\text { EMPREEN } \\
\text { DIMENTO }\end{array}$ & SÓCIOS & $\begin{array}{l}\text { FUNCION } \\
\text { ÁRIOS }\end{array}$ \\
\hline 1 & 31 & Masculino & $\begin{array}{l}\text { Cerveja } \\
\text { Artesanal }\end{array}$ & Superior & Não & 10 meses & 2 & 0 \\
\hline 2 & 33 & Feminino & Saúde & Superior & $\begin{array}{l}\operatorname{Sim} \\
(\mathrm{ME})\end{array}$ & 13 anos & 0 & 5 \\
\hline 3 & 40 & Feminino & $\begin{array}{l}\text { Assistência } \\
\text { técnica e } \\
\text { Extensão rural }\end{array}$ & Superior & Não & 0 & 3 & 4 \\
\hline 4 & 53 & Feminino & Artesanato & $\begin{array}{l}\text { Ensino } \\
\text { Médio }\end{array}$ & Não & 24 meses & 0 & 1 \\
\hline 5 & 37 & Feminino & $\begin{array}{l}\text { Automação } \\
\text { residencial e } \\
\text { comercial }\end{array}$ & Superior & $\begin{array}{l}\text { Sim } \\
(\mathrm{MEI})\end{array}$ & 4 meses & 0 & 3 \\
\hline 6 & 38 & Feminino & $\begin{array}{l}\text { Educação } \\
\text { Tecnológica }\end{array}$ & Superior & Não & $\begin{array}{l}\text { Em fase de } \\
\text { testes }\end{array}$ & 2 & 3 \\
\hline 7 & 31 & Masculino & $\begin{array}{c}\text { Pesquisa } \\
\text { agrícola e } \\
\text { sensoriamento } \\
\text { remoto }\end{array}$ & Superior & $\begin{array}{l}\operatorname{Sim} \\
(\mathrm{ME})\end{array}$ & 1 mês & 2 & 2 \\
\hline 8 & 42 & Feminino & $\begin{array}{c}\text { Startup - } \\
\text { Educação } \\
\text { empreendedora } \\
\text { para mulheres }\end{array}$ & Superior & $\begin{array}{l}\operatorname{Sim} \\
(\mathrm{ME})\end{array}$ & 3 meses & 0 & 15 \\
\hline 9 & 35 & Feminino & Alimentício & Superior & Não & 18 meses & 0 & 2 \\
\hline 10 & 31 & Feminino & $\begin{array}{l}\text { Produção de } \\
\text { mudas }\end{array}$ & Superior & $\begin{array}{l}\text { Sim } \\
(\mathrm{ME})\end{array}$ & $\begin{array}{l}\text { Em fase de } \\
\text { testes }\end{array}$ & 3 & 3 \\
\hline
\end{tabular}

Fonte: Incubadora Ativa - IFMT Campus Barra do Garças.

O Quadro 1 revela algumas informações relevantes para a nossa investigação. Embora escolarizado, nosso público agrega empreendedores iniciantes, em que $80 \%$ têm menos de um ano no seu ramo de negócio. Isso é particularmente importante porque, quanto menor o tempo do empreendimento, menor é a experiência acumulada em relação a conhecimento de clientes e de concorrência, qualidade no oferecimento de serviços, qualidade no atendimento, nas vendas, na divulgação e 
marketing, no uso de tecnologias etc., o que naturalmente os tornam mais vulneráveis em relação aos empreendimentos mais antigos.

No contexto da educação empreendedora, a experiência permite que um estudante execute uma ação e aprenda um princípio ou conceito a partir desta ação e depois reforce o que aprendeu, aplicando-o em alguma situação do mundo real (Morris et al., 2013). A concepção de experiência na educação empreendedora pode ser alimentada por ambientes de aprendizagem que são ricos em diversidade de experiência, de possibilidade de exploração de habilidades pessoais e orientados à geração de novos horizontes de conhecimento (Lima et al., 2014b; Limongi et al., 2012; Oliveira, 2005; Schaefer \& Minello, 2016). (Araújo, Davel, 2018).

Corrobora com esta ideia de inexperiência o fato de 50\% dos empreendimentos ainda não possuírem CNPJ, o que poderia impedi-los de realizar divulgação e comercialização do seu produto em maior escala, como venda para empresas; impedi-los também de estarem aptos a usufruírem de políticas públicas voltadas a empreendimentos regularizados, como financiamentos e aquisição de materiais permanentes com melhores opções de pagamento. Pontuamos ainda o fato de 50\% desses empreendimentos da amostra possuírem sócios e $90 \%$ funcionários; $40 \%$ desse grupo agregam sócios e funcionários! Isso é um fator de impacto numa receita ainda não consolidada, e para nós se traduz em vulnerabilidade. A seguir apresentamos uma síntese dos resultados da análise SWOT realizada com os incubados da nossa amostragem em relação a forças e fraquezas, considerando sinônimos os conceitos de fraqueza e vulnerabilidade.

Quadro 2: Síntese de forças e vulnerabilidades dos empreendimentos da amostra com base em análise SWOT.

\begin{tabular}{|c|c|c|c|}
\hline $\begin{array}{l}\text { INCUBADOS/ } \\
\text { INCUBADAS }\end{array}$ & RAMO & FORÇAS & FRAQUEZAS (VULNERABILIDADES) \\
\hline 1 & Cerveja Artesanal & $\begin{array}{l}\text { Possui } 5 \text { marcas de cervejas, produção } \\
\text { própria, paixão pela produção de } \\
\text { cerveja artesanal e conhecimento } \\
\text { técnico do produto. }\end{array}$ & $\begin{array}{l}\text { Falta de equipamentos, venda limitada (apenas } \\
\text { para amigos, familiares e indicações), tempo } \\
\text { restrito para fabricação (trabalha em outra } \\
\text { atividade), preço elevado do produto artesanal em } \\
\text { relação a outras cervejas consolidadas no } \\
\text { mercado. }\end{array}$ \\
\hline 2 & Saúde & $\begin{array}{l}\text { Possui conhecimento técnico, possui } \\
\text { CNPJ, empresa viável e rentável. }\end{array}$ & $\begin{array}{l}\text { Dificuldade em capacitação em gestão } \\
\text { administrativa e financeira, trabalho de marketing } \\
\text { para captação de clientes. }\end{array}$ \\
\hline 3 & $\begin{array}{l}\text { Assistência técnica e } \\
\text { Extensão rural }\end{array}$ & $\begin{array}{l}\text { Possui comissão técnica qualificada, } \\
\text { realiza captação de recursos públicos, } \\
\text { negócio de impacto. }\end{array}$ & $\begin{array}{l}\text { Não tem formalização jurídica, necessita de } \\
\text { consultorias jurídicas e contábeis, capacitação em } \\
\text { gestão. }\end{array}$ \\
\hline 4 & Artesanato & $\begin{array}{l}\text { Produção própria, produto a baixo } \\
\text { custo e possibilidade de parcerias. }\end{array}$ & $\begin{array}{l}\text { Possui dificuldade em Marketing, apresentação } \\
\text { pessoal e canais de vendas. }\end{array}$ \\
\hline 5 & $\begin{array}{c}\text { Automação residencial e } \\
\text { comercial }\end{array}$ & $\begin{array}{l}\text { Produto e serviços em expansão no } \\
\text { mercado, possui um estagiário para } \\
\text { realização dos trabalhos administrativo } \\
\text { e com marketing e capacitação técnica } \\
\text { da equipe. }\end{array}$ & $\begin{array}{l}\text { Dificuldade na gestão financeira, controle de } \\
\text { estoque, necessita de um programa para } \\
\text { desenvolver esses controles, dificuldade para } \\
\text { fechar parcerias. }\end{array}$ \\
\hline 6 & Educação Tecnológica & $\begin{array}{l}\text { Possui protótipo, possui equipe } \\
\text { qualificada, os principais clientes são } \\
\text { de instituição de ensino e empresas } \\
\text { que invistam em inovação e educação } \\
\text { para colaboradores, iniciou parceria } \\
\text { para teste do produto e conhece a } \\
\text { concorrência. }\end{array}$ & $\begin{array}{l}\text { Empresa em fase de construção e teste, } \\
\text { dificuldade de precificar o serviço/produto, não } \\
\text { possui capital de giro, nada de marketing feito } \\
\text { sobre a empresa. }\end{array}$ \\
\hline
\end{tabular}


Research, Society and Development, v. 10, n. 11, e188101119591, 2021

(CC BY 4.0) | ISSN 2525-3409 | DOI: http://dx.doi.org/10.33448/rsd-v10i11.19591

\begin{tabular}{|c|c|c|c|}
\hline 7 & $\begin{array}{l}\text { Pesquisa agrícola e } \\
\text { sensoriamento remoto }\end{array}$ & $\begin{array}{l}\text { Está inserido numa região agrícola, } \\
\text { poucos concorrentes, possui recurso } \\
\text { para aquisição de equipamentos, } \\
\text { conhecimento Técnico e serviço } \\
\text { inovador no mercado. }\end{array}$ & $\begin{array}{l}\text { Em fase de prototipagem, falta de pessoal para } \\
\text { colaborar no projeto, não tem conhecimento de } \\
\text { gestão, formação de preço de venda, apresentação } \\
\text { pessoal e marketing e não possui identidade } \\
\text { visual/marca, não possui canais de marketing. }\end{array}$ \\
\hline 8 & $\begin{array}{l}\text { Startup - Educação } \\
\text { empreendedora para } \\
\text { mulheres }\end{array}$ & $\begin{array}{l}\text { Possui Plataforma (EDU de Santa } \\
\text { Catarina), possui parceiros (Artesão e } \\
\begin{array}{l}\text { agricultores), micro empresa } \\
\text { registrada. }\end{array}\end{array}$ & $\begin{array}{l}\text { Necessita de profissional ativo para alimentar a } \\
\text { plataforma, necessita lançar mão de novas } \\
\text { ferramentas tecnológicas. }\end{array}$ \\
\hline 9 & Alimentício & $\begin{array}{l}\text { Possibilidade de realizar parcerias no } \\
\text { delivery em restaurantes e lanchonetes, } \\
\text { entende bem dos custos e da } \\
\text { fabricação do produto, possui força de } \\
\text { trabalho e empresa está lucrativa. }\end{array}$ & $\begin{array}{l}\text { Dificuldade em abertura de do CNPJ - MEI por } \\
\text { ser servidora pública, necessita fazer entrega } \\
\text { presencial e adquirir mais equipamentos de } \\
\text { fabricação e conservação do produto. }\end{array}$ \\
\hline 10 & $\begin{array}{l}\text { Produção de mudas e } \\
\text { outras formas de } \\
\text { propagação vegetal } \\
\text { certificadas }\end{array}$ & $\begin{array}{l}\text { Recurso para investimento, } \\
\text { conhecimento técnico, apenas um } \\
\text { concorrente no Estado e parceria com } \\
\text { IFMT - Juína para utilização do } \\
\text { laboratório. }\end{array}$ & $\begin{array}{l}\text { Está em fase de prototipagem, necessidade de } \\
\text { aquisição de equipamentos laboratoriais e } \\
\text { qualificação em gestão. }\end{array}$ \\
\hline
\end{tabular}

Fonte: Incubadora Ativa - IFMT Campus Barra do Garças. Adaptação: Autores.

Nossa análise elegeu palavras chave e a frequência com que apareceram na coluna de vulnerabilidades do Quadro 2. Vejam o Gráfico 1.

Gráfico 1: Frequência das vulnerabilidades identificadas no Quadro 2.

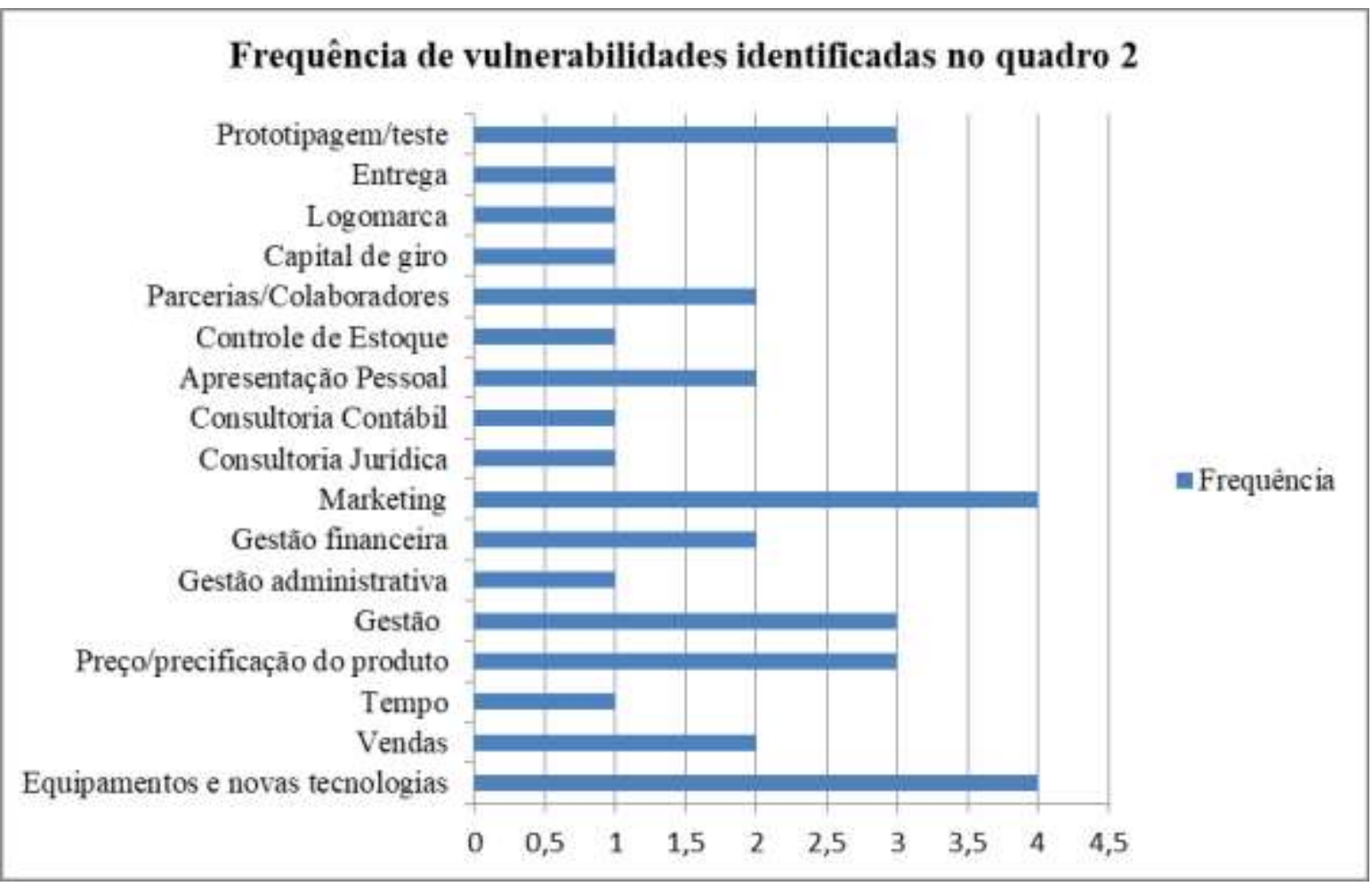

Fonte: Incubadora Ativa - IFMT Campus Barra do Garças. Adaptação: Autores. 
É possível inferir, pela nossa amostragem, que o padrão estabelecido no gráfico 1 aponta para casos particulares na frequência de zero a um, tais como problemas com entrega, falta de logomarca, dificuldade de controle de estoque, necessidade de consultorias e falta de tempo para se dedicar ao negócio. Estas são vulnerabilidades mais comuns a negócios em início de atividade que também são atendidas nas incubações! No entanto, nas frequências seguintes (um a dois, dois a três e três a quatro) constatamos necessidades melhor amparadas por um curso de formação empreendedora, tendo em vista configurarem suportes previstos nas incubações como aporte de melhoramento e potencialização de características empreendedoras.

Raupp e Beuren (2006) apontam que,

as incubadoras de empresas são entidades destinadas a amparar o desenvolvimento de pequenos negócios por meio de um rol de suportes colocados à disposição dos empreendedores. Suas características estão alicerçadas nas necessidades de empresas desse porte, desde o aspecto administrativo e operacional ao financeiro. Além do suporte disponibilizado, devem incentivar características empreendedoras nas empresas incubadas que podem contribuir na busca de vantagens competitivas (Raupp, Beuren, 2006, p. 421).

Neste mesmo estudo, Raupp e Beuren (2006) realizam um levantamento dos tipos de suportes oferecidos por incubadoras brasileiras. No aspecto administrativo oferecem apoio jurídico, assessoria contábil e financeira, assistências em marketing e gestão, orientação empresarial e mercadológica e serviços de secretaria. O suporte financeiro abarca captação e aplicação de recursos, obtenção de capital de risco, juros subsidiados e custos compartilhados. O suporte de estrutura envolve módulos individuais, show room, recepção, salas de reunião, serviços de apoio, de treinamento, de comunicação, de limpeza e segurança, sanitários e copa. Veremos que muitos desses suportes são oferecidos pelo Núcleo Incubador do IFMT.

\subsection{Formação oferecida pela Ativa Incubadora do IFMT}

O curso de competências empreendedoras da Ativa Incubadora do IFMT conta com nove módulos temáticos, todos oferecidos de forma remota aos incubados durante a Pandemia da Covid-19, cujo conteúdo apresenta-se de forma bastante didática e interativa, com exemplos potencialmente contribuidores a percepção do incubado acerca do estudo necessário em detrimento de suas vulnerabilidades. São eles: Validação, Canvas, Prototipagem/MVP, Gestão Financeira e Tributária, Apresentação Profissional, Marketing para o Empreendedor, Ferramentas e Sistemas para Gestão de Negócios, Criatividade e Inovação e Propriedade Intelectual. Apresentamos a seguir uma síntese da abordagem formativa de cada módulo.

Quadro 3: Síntese da formação oferecida pelo Núcleo Incubador - IFMT por meio do curso de competências empreendedoras.

\begin{tabular}{|c|l|l|l|}
\hline$N^{\mathbf{0}}$ & MÓDULO & \multicolumn{1}{|c|}{ DEFINIÇÃO } & \multicolumn{1}{|c|}{ METODOLOGIA DE APLICAÇÃO } \\
\hline 1 & VALIDAÇÃO & $\begin{array}{l}\text { A validação é uma maneira de descobrir se uma ideia } \\
\text { empreendedora é boa ou ruim. Ela pode ser entendida } \\
\text { como uma ação interposta entre a ideia e o problema, } \\
\text { em que a validação do problema deve prioritariamente } \\
\text { balizar uma solução, neste caso a ideia. }\end{array}$ & $\begin{array}{l}\text { A validação é uma pesquisa que carrega nuances } \\
\text { do méto científico, entre eles uma hipótese para } \\
\text { umoblema, coleta de dados (normalmente } \\
\text { questionários), metodologia de coleta e análise de } \\
\text { dados. Essas etapas comprovam, ou não, a } \\
\text { hipótese para o problema, dando vida a ideia. }\end{array}$ \\
\hline 2 & CANVAS & $\begin{array}{l}\text { O canvas é uma ferramenta para modelagem de de } \\
\text { negócios. Traduzido do inglês significa quadro de de } \\
\text { modelo de negócios. O canvas é um mapa visual de } \\
\text { como o empreendimento se estrutura, traduzindo } \\
\text { conceitualmente e estruturalmente o empreendimento. }\end{array}$ & $\begin{array}{l}\text { Mapa visual que aborda conceitos do } \\
\text { empreendimento que definem seu modelo de } \\
\text { negócio, tais como valor, clientes, produção, } \\
\text { parceiros, estrutura dos custos e fontes de receita. } \\
\text { Uma vez preenchido deve ser afixado em local } \\
\text { visível a todos. }\end{array}$ \\
\hline
\end{tabular}




\begin{tabular}{|c|c|c|c|}
\hline 3 & $\begin{array}{l}\text { PROTOTIPAGEM } \\
\text { /MVP }\end{array}$ & $\begin{array}{l}\text { Prototipar é fazer antecipadamente uma representação } \\
\text { do seu produto/serviço a fim de poder testá-lo de modo } \\
\text { a obter feedbacks que vão orientá-lo na tomada de } \\
\text { decisão em relação a este produto/serviço. MVP, } \\
\text { traduzido do inglês, significa Produto Mínimo Viável, } \\
\text { mínimo em custo de produção e viável no sentido de } \\
\text { tornar-se mercadoria. }\end{array}$ & $\begin{array}{l}\text { A prototipagem reduz custos, dado que ainda será } \\
\text { possível reformular o produto/serviço final a } \\
\text { partir dos feedbacks. A metodologia consiste em } \\
\text { tornar a ideia uma realidade por meio de uma } \\
\text { versão mais básica do produto ou serviço. }\end{array}$ \\
\hline 4 & $\begin{array}{l}\text { GESTÃO } \\
\text { FINANCEIRA E } \\
\text { TRIBUTÁRIA }\end{array}$ & $\begin{array}{l}\text { Gestão financeira e tributária é a parte do plano de } \\
\text { negócios em uma empresa cujas diretrizes orientam a } \\
\text { ideia de tornar rentável o negócio, estabelecendo as } \\
\text { ferramentas de controle para garantir a saúde do caixa e } \\
\text { o cumprimento das metas propostas para curto, médio e } \\
\text { longo prazo. }\end{array}$ & $\begin{array}{l}\text { O curso oferece alternativas metodológicas, como } \\
\text { a } 5 \text { W2H e suas sete perguntas (o que será feito, } \\
\text { quando, onde, como, por quem, por qual motivo e } \\
\text { com que custo), o PDCA e a Análise SWOT, } \\
\text { bastante útil para definir pontos fortes e fracos da } \\
\text { sua empresa frente á concorrência. Em se tratando } \\
\text { de gestão financeira, é imprescindível rotinas } \\
\text { como realizar fluxo de caixa, conciliação } \\
\text { bancária, pagar contas, verificar recebimentos e } \\
\text { gerar relatórios. }\end{array}$ \\
\hline 5 & $\begin{array}{l}\text { APRESENTAÇÃ } \\
\text { O } \\
\text { PROFISSIONAL }\end{array}$ & $\begin{array}{l}\text { Trata-se de da apresentação de uma ideia, lançamento de } \\
\text { um produto ou serviço, de modo a despertar interesse do } \\
\text { público alvo. }\end{array}$ & $\begin{array}{l}\text { A metodologia recomendada pelo curso é baseada } \\
\text { no Pitch, que traduzido do inglês significa } \\
\text { arremesso, lançamento. Em negócios é uma } \\
\text { ferramenta de apresentação que agrega cuidados } \\
\text { com o tempo de apresentação e com o conteúdo } \\
\text { apresentado. }\end{array}$ \\
\hline 6 & $\begin{array}{l}\text { MARKETING } \\
\text { PARA O } \\
\text { EMPREENDEDO } \\
\text { R }\end{array}$ & $\begin{array}{l}\text { O Marketing é a estratégia de comunicação do negócio, } \\
\text { elo de interlocução entre a empresa que oferece um } \\
\text { produto ou serviço e seu potencial cliente comprador. }\end{array}$ & $\begin{array}{l}\text { A metodologia do marketing está conceitualmente } \\
\text { subordinada a sua estratégia. Em destaque no } \\
\text { curso a SMP (segmentação, mercado-alvo e } \\
\text { posicionamento). Necessidades dos consumidores } \\
\text { e de diferenciação do produto/serviço balizam a } \\
\text { melhor estratégia de comunicação. }\end{array}$ \\
\hline 7 & $\begin{array}{l}\text { FERRAMENTAS } \\
\text { E SISTEMAS } \\
\text { PARA GESTÃO } \\
\text { DE NEGÓCIOS }\end{array}$ & $\begin{array}{l}\text { Trata-se de softwares capazes de organizar a gestão do } \\
\text { negócio por meio do controle e armazenamento de } \\
\text { dados. Acessar facilmente, com seu smartphone, um } \\
\text { gráfico e uma planilha do seu fluxo de caixa guardado } \\
\text { na sua nuvem é um exemplo deste controle e } \\
\text { armazenamento. }\end{array}$ & $\begin{array}{l}\text { Planilhas eletrônicas, editores de texto, editores de } \\
\text { apresentação, sistemas de armazenamento em } \\
\text { nuvem, etc. são ótimas ferramentas para gerenciar } \\
\text { pequenos negócios. A metodologia, portanto, é } \\
\text { organizar e controlar. }\end{array}$ \\
\hline 8 & $\begin{array}{l}\text { CRIATIVIDADE } \\
\text { E INOVAÇÃOO }\end{array}$ & $\begin{array}{l}\text { A criatividade é uma maneira de promover uma tansição } \\
\text { da realidade atual para uma situação desejada no futuro, } \\
\text { conectando coisas, produzindo ideias novas e úteis que } \\
\text { resultem em um produto ou serviço satisfatório e aceito. } \\
\text { Quando conectamos isso a um número significativo de } \\
\text { pessoas numa determinada época do tempo, estamos } \\
\text { praticando inovação. }\end{array}$ & $\begin{array}{l}\text { A metodologia da criatividade e inovação } \\
\text { encontra sua aplicaçãa no empoderamento de } \\
\text { novidades e no uso delas para a criação, para dar } \\
\text { existência a uma ideia de modo a estabelecer } \\
\text { relações até então não estabelecidas, visando } \\
\text { determinados fins. O mercado online é um bom } \\
\text { exemplo desta metodologia. }\end{array}$ \\
\hline 9 & $\begin{array}{l}\text { PROPRIEDADE } \\
\text { INTELECTUAL }\end{array}$ & $\begin{array}{l}\text { É o direito relacionado a informação e ao conhecimento } \\
\text { que pode ser incorporado a um número ilimitado de } \\
\text { cópias de um objeto e não ao próprio objeto copiado. } \\
\text { Nesse sentido, a propriedade intelectual não se traduz } \\
\text { nos objetos e cópias, mas na informação ou no } \\
\text { conhecimento refletido nesses objetos sendo, portanto, } \\
\text { intangível. }\end{array}$ & $\begin{array}{l}\text { Copiar resguardando o autor da produção } \\
\text { intelectual é diferente de copiar apoderando-se, } \\
\text { dado a si uma autoria de outro. Em negócios } \\
\text { podemos citar como produção intelectual as } \\
\text { marcas comerciais e industriais, símbolos por } \\
\text { meio dos quais as empresas são vistas e } \\
\text { lembradas. Resguardar o direito a propriedade } \\
\text { dessas marcas é fundamental na identificação } \\
\text { dessas empresas nas suas estratégias de } \\
\text { marketing. }\end{array}$ \\
\hline
\end{tabular}

Fonte: Autores.

Adaptado de Incubadora Ativa - IFMT Campus Barra do Garças.

A proposta de educação empreendedora sintetizada no quadro 3 exprime etapas imprescindíveis no processo em que o conhecimento para o empreendedorismo é capaz de agregar valores econômicos ao empreendimento. Autores como Cope (2003) corroboram com esta ideia ao reconhecerem a educação empreendedora como um processo dinâmico de 
conscientização, associação e aplicação capaz de transformar as experiências e conhecimento aprendidos em resultados funcionais.

Krugüer, Büger e Minello (2019) apontam ainda que a educação empreendedora auxilia alunos a desenvolverem conhecimento em determinadas áreas, e que no futuro essas ações podem colaborar com o crescimento econômico e social de um país por meio da implantação e ampliação de ações educadoras em escolas de nível médio, e até mesmo em universidades. A incubação praticada pela Ativa Incubadora do IFMT carrega muito viva esta concepção de educação associada ao empreendedorismo.

Em trabalho recente, Estival et al (2021) analisam e comparam os currículos dos cursos de administração da Universidade Estadual de Santa Cruz (UESC) e Universidade de São Paulo (USP) com objetivo de verificar a prática de disseminação do conhecimento sobre o empreendedorismo, empreendedorismo social e negócios de impacto social em ambos os cursos. Embora tenham encontrado escassez de disciplinas voltadas para o tema, vemos que análises curriculares balizam tomadas de decisões nessa área. O próximo tópico traz uma análise parecida, em que o confronto dos conceitos disseminados no curso de competências empreendedoras com as vulnerabilidades denotam possibilidades de contribuição da formação oferecida.

\subsection{Possibilidades de contribuição da formação oferecida pela Ativa Incubadora do IFMT}

Um cruzamento simples dos dados selecionados no gráfico 1 e a formação descrita no quadro 2 mostra que há relevante convergência entre a formação oferecida e as vulnerabilidades encontradas. Esta convergência tem no escopo da sua estrutura os conceitos de educação e aprendizagem empreendedora e associação entre as instituições de ensino, principalmente universidades, e o fomento ao empreendimento por meio das incubações (Plonski, 1999).

A concepção da educação empreendedora com base nas dimensões do dinamismo, reflexão, integração e liberdade acarreta várias contribuições. Permite um avanço no modelo vigente de ensino-aprendizagem do empreendedorismo, redireciona pesquisas para novos conceitos que conduzam uma melhor prática da educação empreendedora, os quais constituirão em inovações no processo de ensino-aprendizagem do empreendedorismo. Isto proporcionará um melhor engajamento dos estudantes ao processo educacional, que estarão dispostos a aprenderem de forma prática. É uma maneira de repensar caminhos pedagógicos de relação e interação dos agentes envolvidos no processo de ensino e aprendizagem. É preciso que o estudante seja o protagonista do processo de aprendizagem e que o professor seja um mediador, provocador, estimulador e orientador (Freire, 1996), quando valoriza a experiência na educação empreendedora (Araujo, Davel, 2018).

O recorte em destaque (Araujo, Davel, 2018) nos chama atenção à forma como podemos internalizar essa mistura conceitual em nossa análise. Ao proporem uma concepção de ensino-aprendizagem do empreendedorismo alicerçado na prática, os autores não só demonstram uma relevante leitura empírica do processo de incubação, mas engendram uma discussão com importantes teorias de aprendizagem educacionais, entre elas o Behaviorismo (Skinner, 2006), O Sócio Interacionismo (Vigotsky, 2008) e a Aprendizagem Significativa (Silva, 2020).

De natureza materialista e cognitivista, essas teorias valorizam, respectivamente, percepções comportamentais, interação social e concepções prévias construídas a partir da experiência, de modo que sua associação ao caráter prático da aprendizagem alcança mérito teórico e de análise. São teorias valorizadas no campo da pedagogia e das licenciaturas, e dentro das instituições educacionais têm neste lócus o seu maior reconhecimento.

O recorte ainda dá importante contribuição ao contexto quando diz que o estudante deve ser protagonista de sua própria aprendizagem e o professor um mediador. Em outras palavras é ele, o estudante, o maior responsável pela construção própria de conceitos, e pela transformação desses conceitos em aprendizagem a partir da aplicação generalizada do conhecimento em diferentes situações. Estar a frente de um empreendimento ao mesmo tempo que busca desenvolver 
habilidades e competências (na incubação) relacionadas a este empreendimento é um exercício de protagonismo, pois estrutura teoria e prática num vai e vem constante de estudos, reflexão, transformação etc., fundamentais à aprendizagem empreendedora e ao sucesso do negócio. Quando tem dúvida requisita o professor, no caso da nossa incubadora o tutor, que realiza a orientação ou dá conta de uma consultoria cuja orientação seja mais completa, realizando a mediação da construção do conhecimento pelo aluno incubado. Assim é a natureza educacional empreendedora na Ativa Incubadora do IFMT!

Voltando nosso olhar ao confronto que propomos fazer entre as habilidades e competências oferecidas pelo curso de competências empreendedoras e as vulnerabilidades encontradas no gráfico 1, observamos que:

- Em relação à Validação uma das empresas da amostra, do setor de Educação Tecnológica, está em fase de testes, e outra, do setor alimentício, está em fase de projeto (quadro 1). São momentos em que a validação do produto ou serviço é fundamental para confirmação da aceitação/do espaço do mercado para a ideia empreendedora;

- Em relação ao Canvas não apareceu vulnerabilidade em nenhuma das empresas da amostra;

- A Prototipagem/MVP apareceu como vulnerabilidade em três empresas da amostra;

- Em relação à Gestão Financeira e Tributária o diagnóstico acusou como vulnerabilidades gestão financeira (duas empresas), gestão, apenas (três empresas), capital de giro, consultoria contábil, consultoria jurídica e a gestão administrativa (uma empresa cada), e preço/precificação do produto (três empresas);

- Duas empresas acusaram a vulnerabilidade Apresentação Pessoal;

- Em relação ao módulo Marketing para o Empreendedor tivemos as vulnerabilidades vendas (duas empresas) e marketing (4 empresas);

- Em relação ao módulo Ferramentas e Sistemas para Gestão de Negócios identificamos a vulnerabilidade equipamentos e novas tecnologias (quatro empresas), e controle de estoque (uma empresa);

- O módulo Criatividade $\boldsymbol{e}$ Inovação tem relevante aderência às vulnerabilidades entrega (uma empresa), parcerias/colaboradores e vendas (duas empresas cada);

- Em relação ao módulo Propriedade Intelectual tivemos a vulnerabilidade logomarca (uma empresa).

Olhando para o gráfico 1 vemos que apenas o tempo, vulnerabilidade relacionada ao tempo de dedicação do empreendedor ao empreendimento, não encontrou amparo nos módulos do curso. Não se trata especificamente da administração do tempo no empreendimento, mas do tempo disponível para ele. No diagnóstico o empreendedor relatou ter um trabalho fixo se dedicando ao empreendimento apenas nas horas de folga.

A eficiência deste encontro entre formação e necessidade é o primeiro passo certeiro da formação. Vimos que o curso de Competências Empreendedoras do Núcleo Incubador Dinâmica do IFMT possui esta característica. A dinâmica desta formação ainda inclui acompanhamento periódico ao incubado de modo a avaliar constantemente o andamento da formação e das modificações necessárias no empreendimento. O segundo passo, mais importante que o primeiro, é a associação da teoria difundida na formação ao exercício prático, aplicação e verificação da teoria no próprio empreendimento. O protagonismo do empreendedor aparece neste momento.

Autores da área da educação defendem esta ideia de formação alicerçada na prática e na reflexão sobre a prática, proposta viva nas incubações, especialmente na nossa. Freire (2006) escreve que,

É pensando criticamente a prática de ou de ontem que se pode melhorar a próxima prática. O próprio discurso teórico, necessário à reflexão crítica, tem de ser de tal modo concreto que quase se confunda com a prática. [...] Por outro lado, quanto mais me assumo como estou sendo e percebo a ou as razões de ser de porque estou sendo assim, mais me torno capaz de mudar, de promover-me, no caso, do estado de curiosidade ingênua para o de curiosidade epistemológica (Freire, 2006, p. 18). 
Frente às vulnerabilidades do seu empreendimento, o empreendedor, responsável direto pelo constructo que o conduzirá a superação, tem na incubação um parceiro fundamental no processo de reflexão crítica do pensar 'seu estar sendo'. Se mudar faz parte da perspectiva de superação, transitar este 'estar sendo' do conhecimento ingênuo do negócio à epistemologia ${ }^{1}$ do empreender é um pressuposto possível apenas com a presença da prática. Em outras palavras, é preciso pensar e refletir criticamente o curso e o negócio num movimento de vai e vem constante. O próprio questionamento sobre o negócio torna-se mais eficaz e crítico se ocorrer durante a formação, pelas possibilidades de intervenção que terá naquele momento.

Talvez a mais ignorante das pessoas concorde que o ser, e o saber fazer, não sejam possíveis sem a prática. $O$ conhecer teórico, somente em si, apresenta uma dupla limitação: é um saber cuja aplicabilidade ainda não foi testada por quem o sabe, e por não ter sido, ainda está individualizado, ou seja, sem a complexidade de relações com os outros campos do saber, necessária a uma atuação profissional mais crítica.

Segundo Perrenoud (2002), uma prática reflexiva pressupõe uma postura, uma forma de identidade, um habitus. Sua realidade não é medida por discursos ou por intenções, mas pelo lugar, pela natureza e pelas consequências da reflexão no exercício cotidiano da profissão, seja em situação de crise ou de fracasso. Tais situações favorecem a (auto) formação para a identidade profissional, neste caso identidade empreendedora, no sentido de que fornecerá subsídios, dados, ao sujeito que as vivencia, aumentando sua capacidade de tomada de decisão acerca do vir a ser.

Valle (2002) pontua que a identidade profissional faz parte de uma realidade dinâmica e contingente, fora da realidade vocacional. Esta última, segundo a autora, é um tipo de identidade relacionada essencialmente a categorias que herdamos sem as desejar, e que modelam nossas condutas sem que tenhamos consciência disso e sem que possamos controlá-las. Essa complexidade da realidade vocacional faz dela um habitus muito mais condicionado à experiência que simplesmente ao querer, e nos conduz à percepção de que, do ponto de vista educacional, é na identidade profissional que devemos investir. Em outras palavras, não há empreendimento de sucesso sem um empreendedor preparado educacionalmente para promovê-lo. A Ativa Incubadora do IFMT aposta nessa premissa!

\section{Considerações Finais}

Nossas análises e dados mostraram que a contribuição da formação oferecida pela Ativa Incubadora do IFMT está duplamente pautada para a superação de vulnerabilidades, pois de um lado tem um currículo estruturado com conceitos capazes de confrontar as vulnerabilidades de seus incubados, e de outro pratica acompanhamentos que analisam a aplicação prática da formação oferecida, oferecendo soluções por meio de atendimentos diretos e consultorias.

Consideramos que este é um trabalho que orienta corresponsabilidades. Da incubação mostra a importância de um curso estruturado conforme as necessidades do público alvo e também da importância da indissociabilidade da teoria oferecida com a prática desempenhada no empreendimento. Do incubado mostra a relevância das reflexões acerca da tríade estudo, aplicação prática e reflexão sobre os resultados da aplicação, num vai e vem constante durante e após a formação, de modo a se ter um monitoramento do sucesso da ação ou da necessidade de ressignificá-la na ação seguinte.

Orienta também trabalhos futuros, o que deve acontecer ainda nesta etapa de incubação, neste ano de 2021. Minimamente este trabalho dá margem para abordagens voltadas ao monitoramento dos empreendimentos do grupo pesquisado em relação a educação e aprendizagem empreendedora e abordagens que reflitam a teoria empregada aqui como

\footnotetext{
${ }^{1}$ Episteme=saber/conhecimento e Logia=ciência. Empreender envolve conhecimentos científicos à medida que trabalha, por exemplo, com o comportamento das pessoas. Quando o empreendedor domina esses conhecimentos, passa a habitar um lugar diferente do senso comum, menos ingênuo e mais crítico.
} 
resultado do desempenho empresarial em empreendimentos cuja incubação já foram concluídas. Nossa meta para trabalhos futuros é produzir trabalhos com tais abordagens nos próximos meses.

Por fim, esperamos que este trabalho sirva de pontapé inicial ao competente grupo da Ativa Incubador do IFMT, inclusive aos demais campi que num futuro também venham a aderir ao processo de incubação implantado, em relação a produções científicas que divulguem o belíssimo trabalho que já desempenham há anos, e da mesma forma que possa agregar valores intelectual à incubação praticada em todos os Campi do IFMT, em especial ao Campus Barra do Garças. Especialmente neste ano de 2021 deixamos o nosso agradecimento às Pró-Reitorias de Extensão e Pesquisa do IFMT e à Fundação de Amparo à Pesquisa do Estado de Mato Grosso pelo apoio dado.

\section{Referências}

André, Marli Eliza Dalmazo Afonso de. (2005). Estudo de caso em pesquisa e avaliação educacional. Brasília: Liberlivros.

Araujo, Gracyanne Freire de; Davel, Eduardo. (2018). Educação empreendedora, experiência e John Dewey. Revista Pensamento Contemporâneo em Administração. 12 (4), 1-16. https://www.redalyc.org/journal/4417/441760643002/html/.

Bogdan, Robert; Biklen, Sari. (1994). Investigação qualitativa em Educação: uma introdução à teoria e aos métodos. Porto - Portugal: Porto.

Cope, J. (2003). Entrepreneurial learning and critical reflection discontinuous events as triggers for 'higher- level' learning. Management Learning. 34(4), $429-450$.

Costa Júnior, João Florêncio da et al. (2021). A Matriz SWOT e suas subdimensões: uma proposta de inovação conceitual. Research, Society and Development. $10(10), 1-14$.

Estival, Katianny Gomes Santana et al. (2021). Educação empreendedora e negócios de impactos sociais: um estudo sobre o curso de Administração da Universidade Estadual de Santa Cruz, em Ilhéus, Bahia. Research, Society and Development. 10 (1), 1-10.

Flick, U. (2013). Introdução à metodologia de pesquisa: um guia para iniciantes. Tradução de Magda Lopes e Dirceu da Silva. Porto Alegre: Penso.

Fillion, Louis Jacques. (1999). Empreendedorismo: empreendedores e proprietários - gerentes de pequenos negócios. Revista de Administração. 34 (2), 5-28. https://www.academia.edu/1168821/Empreendedorismo_empreendedores_e_propriet\%C3\%A1rios_gerentes_de_pequenos_neg\%C3\%B3cios .

Fonseca, Danilo Amaral da et. al. (2020). A aprendizagem empreendedora na Incubadora de base tecnológica do CRITT/UFJF. Revista Unifeso - humanas $e$ sociais. 5 (5), 40-53.

Freire, Paulo. (2006). Pedagogia da Autonomia: saberes necessários à prática educativa. $33^{\mathrm{a}}$ Ed. Rio de Janeiro: Paz e Terra.

Helms, M. M., Nixon, J. (2010). Exploring SWOT analysis - where are we now? Journal of Strategy and Management. 3 (3) $215-5110$.

Hisrich, P (org.) (1986). Entrepreneurship, intrapreneurship, and venture capital: the fundations of economic renaissance. Lexington: Lexington Books.

Krugër, C., Burger, R. E., Minello, I. F. (2019). O papel moderador da educação empreendedora diante da intenção empreendedora. Revista Economia e Gestão. 19 (52). http://200.229.32.55/index.php/economiaegestao/article/view/18224/14852.

Pereira, A. S.; Shitsuka, D. M.; Parreira, F. J. \& Shitsuka, R. (2018). Metodologia de Pesquisa Científica. [e-book]. Santa Maria. Ed. UAB/NTE/UFSM. https://repositorio.ufsm.br/bitstream/handle/1/15824/Lic_Computacao_Metodologia-esquisa-Cientifica.pdf?sequence=1 .

Perrenoud, Philippe. (2002). A Prática Reflexiva no Ofício de Professor: Profissionalização e Razão Pedagógica. Porto Alegre: Artmed.

Plonski, Guilherme Ary. (1999). Cooperação Universidade-Empresa: Um Desafio Gerencial Complexo. Revista de Administração. 34 (4), 5 - 12. https://repositorio.usp.br/item/001069034.

Raup, Fabiano Maury; Beuren, Ilse Maria. (2006). O suporte das incubadoras brasileiras para potencializar as características empreendedoras nas empresas incubadas. Revista Adm. 41 (4), 419-430.

Sampieri, R. H.; Collado, C. F. \& Lucio, M. P. B. (2013). Metodologia de Pesquisa. 5 ed. Porto Alegre, AMGH.

Silva, João Batista. (2020). A teoria da aprendizagem significativa de David Ausubel: uma análise das condições necessárias. Research, Society and Development. 9 (4), 1-13.

Skinner, Barrhus Frederic. (2006). Sobre o behaviorismo. 10 ed. São Paulo: Cutrix.

Valle, Ionde Ribeiro. (2002). Da “identidade vocacional” à “identidade profissional”: a constituição de um corpo docente unificado. Revista Perspectiva. 20 (n. Especial), 209-230.

Vigotsky, Lev Semenovitch. (2008). Pensamento e Linguagem. 4 ed. São Paulo: Martins Fontes. 